
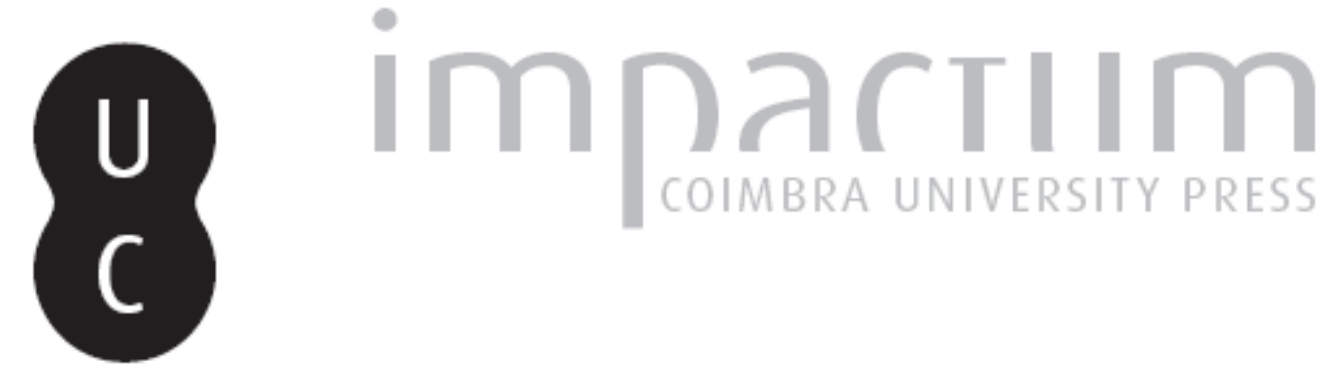

\title{
Persuadir pela palavra e pela imagem: de Oratore de Cícero
}

Autor(es): $\quad$ Miranda, Margarida

Publicado por: Associação Portuguesa de Estudos Clássicos; Instituto de Estudos

URL persistente:

URI:http://hdl.handle.net/10316.2/30476

DOI:

DOI:http://dx.doi.org/10.14195/0872-2110_49_13

Accessed : $\quad$ 26-Apr-2023 12:00:42

A navegação consulta e descarregamento dos títulos inseridos nas Bibliotecas Digitais UC Digitalis, UC Pombalina e UC Impactum, pressupõem a aceitação plena e sem reservas dos Termos e Condições de Uso destas Bibliotecas Digitais, disponíveis em https://digitalis.uc.pt/pt-pt/termos.

Conforme exposto nos referidos Termos e Condições de Uso, o descarregamento de títulos de acesso restrito requer uma licença válida de autorização devendo o utilizador aceder ao(s) documento(s) a partir de um endereço de IP da instituição detentora da supramencionada licença.

Ao utilizador é apenas permitido o descarregamento para uso pessoal, pelo que o emprego do(s) título(s) descarregado(s) para outro fim, designadamente comercial, carece de autorização do respetivo autor ou editor da obra.

Na medida em que todas as obras da UC Digitalis se encontram protegidas pelo Código do Direito de Autor e Direitos Conexos e demais legislação aplicável, toda a cópia, parcial ou total, deste documento, nos casos em que é legalmente admitida, deverá conter ou fazer-se acompanhar por este aviso.

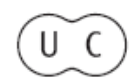




\section{Boletim de}

\section{Estudos Clássicos}

Associação Portuguesa de Estudos Clássicos Instituto de Estudos Clássicos

Coimbra

Junho de 2008 


\section{Persuadir Pela Palavra e pela Imagem: DE ORATORE DE CÍ́CERo}

Compor e interpretar emblemas era uma das actividades específicas da classe de Retórica. Em dias de maior solenidade no colégio, aquelas pinturas eram afixadas e exibidas em local público, após serem examinadas e seleccionadas por duas pessoas designadas pelo reitor. "Interpretar hieróglifos, símbolos pitagóricos, apoftegmas, adágios, emblemas ou enigmas" é um dos exemplos de exercícios que o professor de retórica devia prescrever aos seus alunos, sob a forma de disputa, tal como "distinguir figuras [de retórica] e criar [novas]; enunciar os preceitos de retórica para as cartas, os poemas e a história, e fazer a sua aplicação; ou expor trechos mais difíceis dos autores e esclarecer as dificuldades; (...) ou fazer declamações" (Ratio Studiorum, XVI, 12).

Para que a exibição destes trabalhos fosse mais frequente a Ratio determinava que, de dois em dois meses, se procedesse à afixação, nas paredes da sala de aula, das melhores poesias compostas pelos alunos, acompanhadas, segundo o costume local, de algumas breves composições em prosa, "como inscrições para gravar em escudos [heráldicos], igrejas, túmulos, jardins, estátuas; (...) Algumas vezes, poder-se-ão acrescentar desenhos para ilustrar o emblema ou o assunto proposto" acrescenta o texto (Ratio, XVI, 18).

Aparentemente este era um género de actividade reservado à formação avançada dos estudos humanísticos. Por isso, também aos membros das Academias se prescrevia a criação de emblemas e divisas, a composição e interpretação de inscrições e de enigmas; e a composição de símbolos, de modo que cada um desse a sua interpretação sobre uma determinada matéria (XIX, 3).

A tal ponto era apreciado este género de actividade literária que era mesmo proposto aos alunos de retórica como actividade lúdica, no dia da sua pausa semanal. Interrompendo o programa dos historiadores ou dos poetas, as actividades desse dia destinavam-se a favorecer a erudição, devendo assumir então um carácter "mais rebuscado", diz o texto (XVI, 15). Entre os exemplos 
apontados ocupa o primeiro lugar a apresentação de hieróglifos e de emblemas.

A temática destas composições, quase sempre de finalidade persuasiva, gozava da maior liberdade. Umas versavam sobre as virtudes cardeais, as faculdades humanas (memória, inteligência, vontade), a guerra e paz, os mistérios da fé ou a vida dos santos. Noutras ocasiões os artistas deviam inspirar-se nas próprias matérias abstractas que faziam parte do programa lectivo, como a obra de Cícero e o seu pensamento retórico-filosófico.

$\mathrm{Na}$ sequência dos emblemas escolhidos e comentados nos números anteriores do Boletim de Estudos Clássicos ${ }^{1}$, seleccionámos alguns emblemas que integraram a exposição realizada em 1663 no Colégio Jesuítico de Bruxelas e cujo conteúdo corresponde ao De Oratore de Cícero, livro de estudo da classe de Retórica.

A colecção de emblemas conservados e modernamente publicados por Karel Porteman ${ }^{2}$ abre com o lema: Orator fit, poeta nascitur, outrora atribuída a Cícero. O aforismo pressupõe a ideia de que a poesia é dom da natureza, enquanto a eloquência é fruto de uma arte que se desenvolve com o estudo e a prática. Na verdade, embora o debate seja antigo, a expressão não se encontra em nenhum escritor clássico, mas ela exprime o pensamento pedagógico sustentado pelos colégios. De facto, a poesia ocupa nos programas da Ratio um lugar secundário em relação à oratória, não tanto devido ao desinteresse dos mestres pela arte poética em si mesma, mas devido à convicção de que todos os homens, se ensinados, podem chegar a alcançar clareza de expressão e poder da persuasão, mas nem todos poderão chegar a ser poetas.

Os emblemas seleccionados expõem como título um pensamento do $D e$ Oratore e acrescentam, na parte inferior, uma breve citação, quase sempre de um poeta latino.

1 "Persuadir pela palavra e pela imagem: doctrina" e "Persuadir pela palavra e pela imagem: memoria" BEC 47 (2007) 109-114 e BEC 48 (2007) 127-134 respectivamente.

2 Emblematic exibitions at the Brussels Jesuit College (1630-1685), Brepols, 1996. 


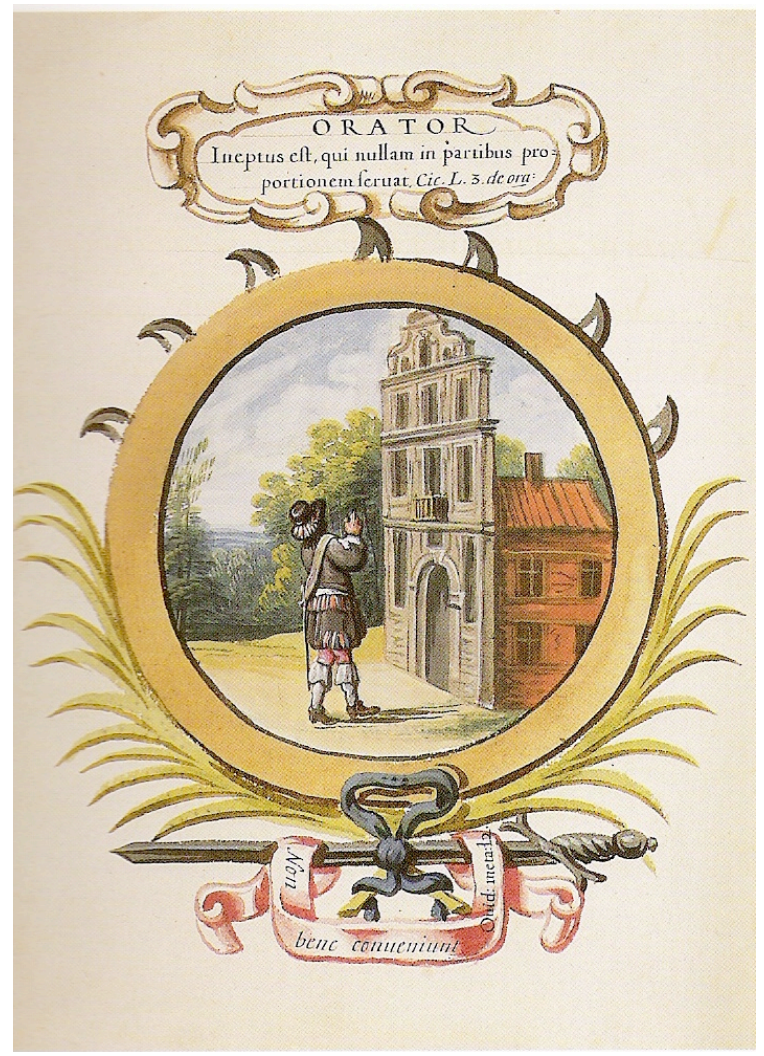

Fig.1: ORATOR ineptus est qui nullam in partibus proportionem seruat

Orador incompetente é aquele que não observa a proporção entre as partes. A ideia é ilustrada por uma casa cuja fachada é muito maior que o restante edifício. A legenda inferior acrescenta-lhe um verso de Ovídio, que se encontra completamente retirado do seu contexto: Non bene conueniunt (Metam. 2, 486), isto é, "não ficam bem juntos". 


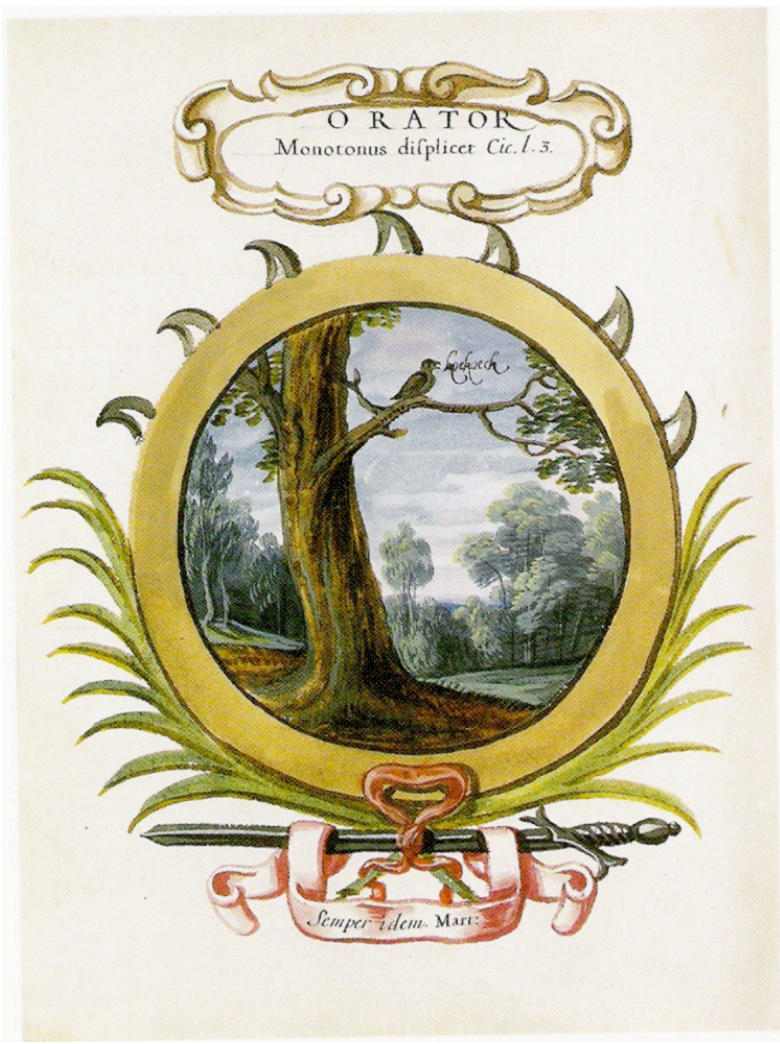

Fig. 2: Orator monotonus displicet

O mau orador é comparado ao cuco, e o discurso maçador, ao seu canto repetitivo, que o artista legendou em holandês vernáculo. $\mathrm{O}$ poeta escolhido para ilustrar o tema foi Marcial: semper idem. 


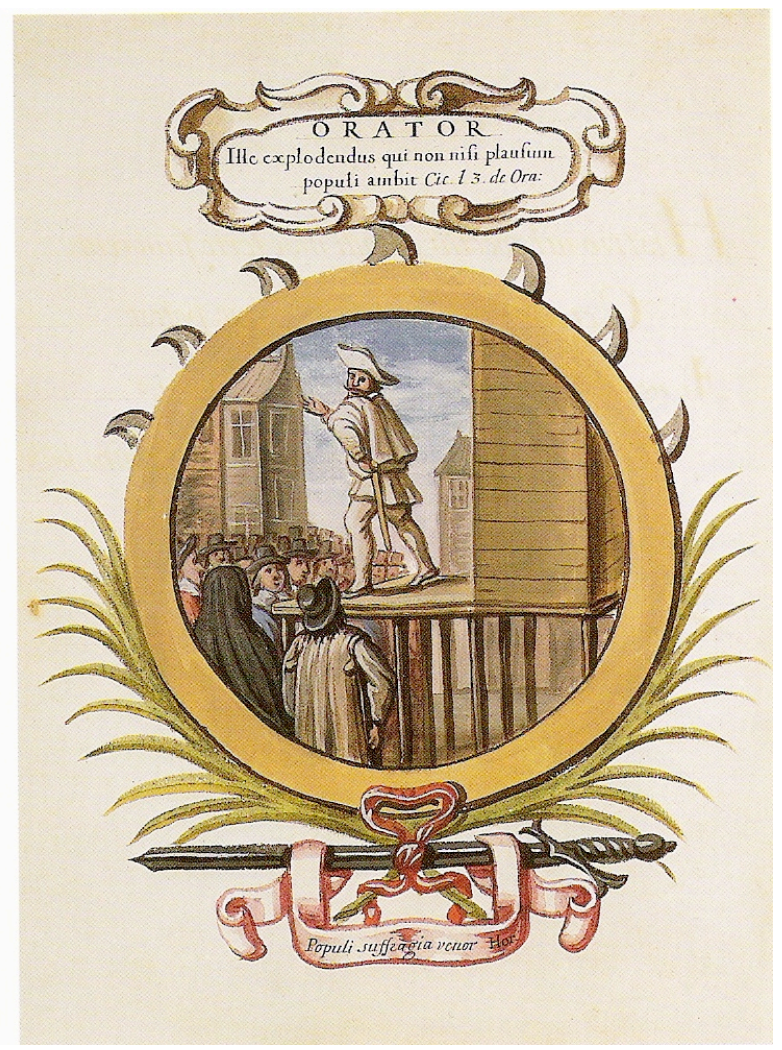

Fig. 3: Orator ille explodendus qui non nisi plausum poluli ambit

O orador que apenas deseja os aplausos do público é representado como um actor. Mas sobre ele o juízo é intransigente: explodendus, deve ser apupado. Assim acontece efectivamente com o actor, cujo único objectivo é obter o favor do público. Por isso, os versos escolhidos são de Horácio: Populi suffragia uenor (Epist., I, 37): Ando em busca de popularidade.

Os artistas traduziam assim de forma clara e visual os preceitos mais elementares da criação oratória: desproporção, monotonia e aplauso fácil são alguns dos vícios a evitar. 